\title{
ESTRATÉGIAS PÓS-FENOMENOLÓGICAS PARA CARTOGRAFAR UMA REGIÃO: NARRATIVAS, MAPEAMENTOS
} E PERFORMANCE

Post-phenomenological strategies to map a region: narratives, mappings, and performance

Jörn Seemann'

\section{RESUMO}

Nas últimas duas décadas, a geografia regional tem recebido novos impulsos para repensar e pesquisar regiões. Sob a influência de teorias pós-modernas e pós-estruturalistas, geógrafos humanos começaram a abordar o conceito de região a partir de discursos, narrativas e representações socioculturais. Este artigo tem como objetivo contribuir para o debate sobre as relações entre sentido de lugar, região e fenomenologia. Argumenta-se que mapas e uma base pós-fenomenológica além das representações convencionais podem abrir novas perspectivas para o estudo geográfico de regiões. Através do exemplo da região do Cariri, no Sul do Ceará, serão apresentadas três estratégias cartográficas diferentes e complementares (narrativa, mapeamento e performance) para trabalharcom imagense imaginação regionais.

Palavras-chave: Geografia regional. Pós-fenomenologia. Cartografia. Mapeamentos culturais. Cariri (Ceará).

\section{ABSTRACT}

During the last two decades regional geography has received new impulses to rethink and study regions. Under the influence of postmodern theories and post-structuralism, human geographers have started to approach the concept of region through discourse, narratives, and sociocultural representations. This article aims to contribute to the debate on the relationship between sense of place, region, and phenomenology. I argue that maps and a postphenomenological base beyond conventional representations may open up new perspectives for the geographical study of regions. I will use the example of the Cariri region in Southern Ceará to present three different and complementary cartographic strategies (narrative, mapping, and performance) in order to deal with the regional images and imagination.

Keywords: Regional geography. Post-phenomenology. Cartography. Cultural mappings. Cariri region (Ceará).

\footnotetext{
1 Professor Adjunto do Departamento de Geociências da Universidade Regional do Cariri (URCA). jornseemann@gmail.com.

$\checkmark$ Universidade Regional do Cariri, Departamento de Geociências, Rua Cel. Antônio Luiz, 1161, Pimenta, Crato, CE. 63105-000.
} 


\section{PRIMEIRO E-MAIL, 02 DE ABRIL DE 2012²}

\section{Cara amiga,}

Hoje recebi um desafio bastante grande de um amigo e colega do Sudeste. Ele me convidou para uma mesa redonda sobre sentido de lugar, região e identidade por ocasião do III Seminário Nacional sobre Geografia e Fenomenologia. Não fiquei muito preocupado com o fato de precisar lidar simultaneamente com três conceitos diferentes (lugar, região e identidade), já que na minha tese de doutorado (SEEMANN, 2010) tive a oportunidade de tratar de uma tríade semelhante-mapas, cultura e região -, cujas afinidades e divergências eu explorei em detalhe, com a finalidade de desenvolver estratégias para cartografar culturas na região do Cariri no Ceará. Minha pesquisa girava em torno de representações (carto) gráficas regionais e sua inserção na cultura caririense.

Para a minha apresentação no evento, quero alcançar o seguinte objetivo: abordar o conceito da região a partir das representações gráficas e cartográficas, produzidas através do imaginário e da imaginação das pessoas que habitam um espaço vivido ou se deslocam dentro dele.

Obviamente o ponto de partida mais fácil para preparar a minha fala seria o conceito de região e logo comecei a mergulhar no assunto. Não preciso lhe contar que há uma bibliografia substancial sobre esse assunto no Brasil (por exemplo, CORREAA, 1986; GOMES, 1995; THRIFT, 1996; LENCIONI, 1999, HAESBAERT, 2010). Sabendo do "ranço tradicional" da geografia regional, decidi folhear algumas edições da Revista Brasileira de Geografia dos anos 50 para entender

2 Decidi escrever meu texto em forma de uma correspondência por e-mail, porque é um estilo mais leve para dialogar sobre região e fenomenologia. Inspirei-me em Reichart (1999) e Turra Neto (2001) que usaram a técnica de cartas escritas para um amigo fictício para apresentar as suas reflexões.

Geograficidade | v.3, n.2, Inverno 2013

ISSN 2238-0205 como esse modo de fazer geografia se (re) produzia no passado. $\mathrm{Na}$ amostra de artigos que encontrei, os autores discursavam sobre temas como o problema da terra no Brasil (LEITE, 1959), a pesca no litoral fluminense (BERNARDES; BERNARDES, 1950), os solos do município de Itapecerica, SP (SETZER, 1951), ou a influência da cidade de Jequié na zona cacaueira da Bahia (SANTOS, 1956). Quase todos os textos estavam relacionados com um recorte do espaço brasileiro: fazendas, cidades, municípios, regiões, estados, o país. Não havia uma discussão sobre questões teóricas ou metodológicas. Os autores foram diretamente ao que interessava: o reconhecimento, a observação e a descrição de lugares específicos e suas geografias física e humana. Seria errado dizer que nesses artigos não havia uma problematização da geografia. Pelo contrário, os títulos dessas publicações mostraram uma preocupação que vai além de uma mera descrição. Falava-se de estudo, contribuição, interpretação, distribuição ou de "problemas", evidentemente não no sentido da geografia crítica do presente, mas para indicar que a geografia era uma ciência que exigia raciocínio e força de dedução para compreender a configuração e dinâmica do espaço. Ao folhear os artigos vi que eles incluíram um número considerável de tabelas, fotografias e mapas para visualizar e explicar a temática. Nessa abordagem, a região era concebida como uma realidade objetiva (CLAVAL, 2007). Nos textos, os autores ficaram dissociados do espaço vivido, observadores externos, desinteressados e separados da realidade, como se contemplassem o mundo a partir de uma "vista de lugar nenhum" (DODGE; PERKINS, 2009), que é uma característica distinta dos humanos. Diferente dos outros seres vivos, 0 ser humano é capaz de pensar o mundo de uma forma que transcenda a experiência direta e que o posicione em um local que é de nenhures, isto é, em lugar nenhum (NAGEL, 1989). 
Quando li os artigos da Revista Brasileira de Geografia, ganhei a impressão de que os geógrafos que escreveram esses textos, nunca pisaram esses espaços, igual ao geógrafo que o Pequeno Príncipe encontrou no sexto planeta da sua viagem: uma espécie de tabelião que apenas anotava o que os viajantes e testemunhas oculares the contavam (SAINT-EXUPÉRY, 1967). Claro que esses pesquisadores dos anos 50 não eram geógrafos de gabinete. Eles não cansaram de enfatizar a importância do trabalho de campo e das excursões geográficas. O problema é a forma de apresentação. Neste contexto, o geógrafo americano John Hudson (2002, p. xiii) faz uma observação interessante: "A geografia regional começa com a premissa de que é possível captar o sentido de um lugar através da leitura sobre esse lugar." Será que um texto bem escrito poderia abrir as portas para o espaço real? Pois bem, não consegui "entrar" nesse espaço vivido apresentado nos artigos da Revista Brasileira de Geografia. Mais uma vez Hudson me ajuda: "a fraqueza mais óbvia [dessa abordagem] é que é muito difícil tecer um fio de meada, uma story line [narrativa] nesse roteiro para tornar os fatos vivos" (HUDSON, 2002, p. xiii). Resta a questão: como estabelecer uma ligação entre região e sentido de lugar? Ficaria feliz se pudesse me dar uma dica.

Abraços regionais do seu amigo Jörn.

\section{E-MAIL 2, 20 DE AGOSTO DE 2012}

\section{Cara amiga,}

Agradeço muito pelas suas sugestões. Como minha formação acadêmica está mais próxima da geografia anglo-saxônica, não pensei na contribuição dos geógrafos franceses para discutir a região. Que mancada! Obrigado por ter mandado a referência ao livro de Armand Frémont sobre a região como espaço vivido (FRÉMONT, 1976). Um amigo meu de Presidente Prudente localizou uma cópia do livro e me mandou a obra completa escaneada. Logo em seguida comecei a leitura. A propósito, quero lhe dizer que todas as citações das obras em francês e inglês que uso são traduções da minha autoria. Tradutor - traidor?

O que Frémont escreve sobre a região como espaço vivido? O contexto do livro é a França hiper-centralizada dos anos 60 e 70, na qual a região era concebida "como objeto político, matéria operacional para técnicos, terreno de insatisfação para reivindicações ou revoltas, discurso de homens políticos nos locais" (FRÉMONT, 1976, p. 9). Protestos estudantis, greves operárias e movimentos regionalistas caracterizaram essa época. O conceito de região foi redescoberto, porque a região "era considerada uma entidade que não se identificava com o território nacional" (FRÉMONT, 1976, p. 10). O Estado-Nação como estigma e a região como expressão de identidade. Neste contexto, Frémont propõe a geografia como ciência voltada a questões regionais. Para ele, a geografia é "o estudo da estrutura de regiões como um sistema particular de relações que unem o homem e o lugar em um espaço específico" (FRÉMONT, 1976, p. 13). Ele afirma que "a região, caso ela exista, é um espaço vivido. Visto, percebido, sentido, amado ou rejeitado" (FRÉMONT, 1976, p. 14), que tanto é moldado pelos seres humanos como também molda as pessoas através das suas imagens. Concluindo esse pensamento, ele afirma que "redescobrir a região, então, é procurar capturá-la onde ela existe, vista pelo homem" (FRÉMONT, 1976, p. 14). "Caso ela exista." Até o Frémont tem dúvidas! A região é concebida como um mentefato, perceptual e vernacular, que não é uma "criação intelectual do geógrafo profissional", baseada em "critérios quantificáveis cuidadosamente escolhidos", mas "o produto da percepção espacial de pessoas comuns" (JORDAN, 1978, 
p. 293). Regiões são compósitos ou sínteses dos mapas mentais da sua população.

Frémont demora em chegar ao cerne da sua proposta. Ele começa com a noção de espaço na psicologia, na psicanálise e na sociologia, discutindo autores desde Piaget e Lévi-Strauss a Marx e Freud. Como essas pesquisas carecem de uma base teórica mais espacial, ele recorre ao espaço econômico e suas diversas modelagens sobre centralidade, hierarquias e polarizações. Esse apanhado serve para abrir o caminho para a ciência geográfica como catalisador dessas idéias. Para Frémont, o "método geográfico" (FRÉMONT, 1976, p. 75-97) consiste "no olhar e nas palavras" e engloba, entre outros aspectos, biografias e trajetórias de vida e os seus respectivos valores, técnicas como questionários e conversas em grupo, fontes como a literatura e os produtos da mídia.

Confesso que esperei ler mais sobre esse "método geográfico". Para mim, parecia mais como um "balaio" de idéias soltas sobre o espaço regional. Senti falta de uma base teórica mais geográfica e crítica e continuei pesquisando na internet. Li que no começo da década dos anos 80, surgiu um movimento de renovação nos estudos regionais. Geógrafos postularam uma "nova geografia regional", atrelada a abordagens críticas nas ciências sociais (PUDUP, 1988; GILBERT, 1988, SAYER, 1989). Sob essa perspectiva, "o objetivo foi ver a região como médium e resultado de práticas sociais e relações de poder que operam em escalas espaciais e temporais múltiplas, entre as quais a região poderia servir como uma forma de aporte" (HENDERSON, 2009, p. 631). O foco das pesquisas mudou do espaço físico e concreto para os mecanismo e processos sociais responsáveis pela configuração regional. Os geógrafos compreenderam que relações sociais, estruturas institucionais, ideologias, símbolos e identidades têm um enorme impacto no surgimento, na existência e no desaparecimento de regiões (PAASI, 2002). Essas regiões, suas narrativas e imagem, por sua vez, também produzem discursos e práticas em reciprocidade. Fiquei fascinado com a idéia de imagens regionais. A geógrafa americana Marie Price (1996) afirma que geógrafos raramente investigam as origens de uma região e os processos interpretativos e imaginativos atrás da sua construção. Para ela, a análise regional seria "um ato de imaginação que atribui um sentido a um espaço não diferenciado. [...] Como nações, regiões são comunidades imaginadas, [...] construídas por múltiplos atores que, intencionalmente ou não, estimulam um sentido de relacionamento ou pertencimento físico e humano através do espaço" (PRICE, 1996, p. 334-335). Claro que isso é uma alusão a um livro de Ben Anderson, Comunidades Imaginadas (ANDERSON, 2008). Neste sentido, a região se torna uma maneira de ver e um dispositivo de organizar os nossos pensamentos sobre o mundo (HENDERSON, 2009, p. 631).

Sabe uma coisa? Agora estou vendo a conexão entre a região e a fenomenologia. Vou encerrar esse e-mail para aproveitar deste momento de inspiração. Eu lhe escrevo assim que tiver novidades.

Abraços vividos do seu amigo Jörn.

\section{E-MAIL 3, 30 DE AGOSTO DE 2012}

\section{Cara amiga,}

Você tem razão. Talvez o conceito de região não tenha sido o ponto de partida mais promissor para o meu estudo. Confesso que o que me incomodava na preparação da minha fala foi a ênfase na fenomenologia "clássica". Como geógrafo humanista assumido (talvez mais crítico do que humanista do que fui dez anos atrás), sempre lutei com as diversas vertentes fenomenológicas. Mostrei simpatia com a fenomenologia da percepção de Merleau-Ponty (1994) e a poética do espaço de Bachelard (1978), mas achei que a forma como esses autores 
expressaram as suas idéias era muito densa. Tive que ler e reler muitas passagens desses livros para entender o significado das palavras. Ao mesmo tempo, essas leituras deixaram muitas perguntas em aberto. A minha principal dúvida era a questão de como aplicar a fenomenologia na prática.

No campo da geografia, a fenomenologia sempre andou de mãos dadas com a vertente humanista. Quando se estabeleceu como campo depesquisa nos anos 70 do século passado, a geografia humanista surgiu como uma reação a outras correntes emergentes como a geografia quantitativa e marxista. Os interesses dos geógrafos humanistas giravam em torno de experiências humanas e subjetivas do lugar, em busca de uma compreensão mais profunda do sentido de lugar, das comunidades humanas, das paisagens culturais e da vida cotidiana com seus valores. Puxa, os geógrafos humanistas estudaram mesmo o mundo! Eles até cismaram sobre a "iconografia da paisagem, mapas mentais, percepção ambiental e geografias do dia-a-dia, empregando uma gama de métodos, incluindo a fenomenologia, etnografia e a hermenêutica." (ADAMS; HOELSCHER; TILL, 2001, p. xv)

Neste contexto, a fenomenologia se tornou uma das principais bases filosóficas da geografia humanista para investigar o ser-no-mundo, a essência da experiência humana, a interação com e a políticas dos lugares ( $p . x v)$.

Portanto, no começo do século XXI, realizou-se uma mudança de foco nas pesquisas. Geógrafos simpatizantes da vertente agora ficam menos interessados no humanismo e mais nas humanidades. Eles mostram menos interesse pela filosofia e mais pelas manifestações materiais e imateriais, com ênfase na construção social de mundos, lugares, paisagens, significados e experiências humanas e como esses constituem contextos culturais específicos ( $p . x v i)$. Devido à influência de novas teorias sociais críticas como o feminismo,
- materialismo cultural e o pós-estruturalismo, surgiram novas ontologias, epistemologias e metodologias e maneiras diferentes de definir e conceber a experiência humana. Para muitos desses geógrafos humanos críticos não era mais uma busca por valores universais, como, por exemplo, a noção heideggeriana de habitar, mas a procura por uma abordagem crítica que poderia ajudar a abandonar "a camisa-de-força de posições filosóficas pré-existentes" (CLOKE; PHILO; SADLER, 1991, p. 81). Qual seria a cara dessa "geografia póshumanista" (BARNES; GREGORY, 1997)? Ou será que deveria dizer "geografia pós-fenomenológica" (ROSE; WYLIE, 2011)? Em primeiro lugar, o prefixo "pós" (penso também no pós-marxismo, no pósmodernismo ou no pós-estruturalismo) não significa uma ruptura com as teorias anteriores, mas procura uma releitura das suas bases. Não visa rejeitar essas idéias, mas repensar as perspectivas vigentes e muitas vezes hegemônicas. No caso da pós-fenomenologia, Mitch Rose e John Wylie admitem que embora se trate de um termo "de difícil manejo", a palavra pós-fenomenologia

nos ajuda a captar o sentido de um movimento que se inicia dentro das geografias inspiradas pela fenomenologia, indo para além dos preceitos e princípios 'clássicos' dessa filosofia, com foco no sujeito e como esse percebe o mundo, exposto nas obras de Heidegger e Merleau-Ponty. (ROSE \& WYLIE, 2011, p. 230)

Saem os "clássicos", entram os filósofos "da moda" como Gilles Deleuze, Jacques Derrida, Emmannuel Levinas e Jean-Luc Nancy. E há muitos outros batendo na porta. Há pelo menos três aspectos que se destacam nessa nova fenomenologia: afetividade, um foco no mundo material e questões metodológicas.

Quanto ao primeiro aspecto, geógrafos começaram a fazer questão de ficarem literalmente presentes nas suas pesquisas. Em vez de 
Estratégias pós-fenomenológicas para cartografar uma região: narrativas, mapeamentos e performance Jörn Seemann

apenas estudar emoções, afeto, e relações pessoais, as suas pesquisas lidam com os seus próprios valores e experiências. É uma mudança significativa, quando se leva em consideração que os geógrafos humanistas costumavam separar sujeito e objeto nos seus trabalhos. Nos anos 80, o geógrafo americano Denis Wood (1982) escreveu uma resenha virulenta sobre um livro organizado pela geógrafa humanista irlandesa Anne Buttimer, na qual, no seu estilo irreverente, atacou os geógrafos humanistas e seus aportes fenomenológicos, acusando as suas falhas:

Os seguidores [da geografia humanista] querem entrar nos outros, mas eles não deixam os outros entrarem neles; eles querem compartilhar o mundo do outro, mas não deixam os outros compartilharem o seu mundo; eles querem bisbilhotar e pegar na vida de um residente em um projeto de moradia, escutar as histórias dos idosos, engatinhar sob a pele de um alcoólatra, mas não mostram o mínimo interesse para expor as formas de vida do estudante de pós-graduação ou do professor universitário ao escrutínio excruciante do mundo admirado. (WOOD, 1982, p. 506)

A provocação de Wood se direciona à suposta objetividade do observador. Por que o pesquisador não entrava como parte integrante e indissociável do espaço vivido e os outros seres humanos? Para deslocar o foco da experiência gerada por um sujeito pré-existente, os pesquisadores agora enfatizam o "mais-que-humano", uma segunda característica da abordagem humanista mais recente. Mais-quehumano? O que é isso? Na verdade, trata-se de uma "virada material" na geografia (WHATMORE, 2006): os geógrafos humanos críticos investigam como objetos, forças e processos moldam e geram modos de ser humano (LEA, 2009). Em vez de ler o mundo a partir da mente humana, trata-se de uma reflexão sobre mente humana a partir do mundo.
Essa abordagem diferenciada também implica uma discussão mais ampla sobre os procedimentos para pesquisas, que é o terceiro aspecto que gostaria de destacar. Métodos convencionais da geografia humana como a observação participante ou entrevistas se mostraram insuficientes para revelar a complexidade das práticas sócio-culturais. Porconsequência, foram introduzidos recursos inovadores: tecnologias como o vídeo para documentar pesquisas, métodos experimentais emprestados de áreas como o teatro, a coreografia ou a arte e novas formas para narrar essas experiências, não necessariamente como textos (LEA, 2009). Essas metodologias diferentes desafiam o pensamento convencional da geografia e literalmente visam ir além das representações para captar momentos que não são representáveis. Como o número de páginas em um artigo científico é limitado, não posso entrar nos detalhes dessa teoria não-representacional, que alguns geógrafos britânicos criaram na década de 9o. Existe uma vasta literatura sobre o tema em inglês (por exemplo, THRIFT, 2007; ANDERSON; HARRISON, 2010). A apresentação e revisão dessas idéias seria um tema oportuno para um estudo mais aprofundado. O geógrafo cultural escocês Hayden Lorimer resume bem o caráter dessa abordagem não-representacional:

O foco está na questão de como a vida adota formas e ganha expressão em experiências compartilhadas, rotinas cotidianas, encontros fugazes, movimentos corporificados, gatilhos précognitivos, habilidades práticas, intensidades afetivas, impulsos duradouros, interações não excepcionais e disposições sensuais. (LORIMER, 2005, p. 84)

Acho que já lhe mandei material suficiente para reflexão. A pergunta que lhe mandei no meu último e-mail ainda está pairando no ar: como seria essa pós-fenomenologia na prática?

Abraços pós-fenomenológicos do seu amigo Jörn. 


\section{E-MAIL 4: 9 DE SETEMBRO DE 2012}

\section{Cara amiga,}

Em busca de uma fenomenologia em ação que se defina pela prática e não pela filosofia, encontrei a cartografia como minha aliada. Portanto, devo mencionar que a minha concepção de cartografia não corresponde ao modelo normativo da disciplina, com o seu rigor matemático e a visão cartesiana do espaço. Não utilizo os mapas para medir distâncias e determinar coordenadas, mas para comunicar e expressar idéias, conceitos e valores que são o resultado de discursos e visões de mundo. Há múltiplas camadas e múltiplas vozes. Mapas como parte da cultura visual de uma sociedade sempre são interpretações e traduções contestadas da realidade. Mais adiante vou explicar melhor essa perspectiva cultural da cartografia.

Tive que pensar em um lugar adequado para testar as minhas idéias na prática. A escolha foi fácil devido a minha familiaridade com o Cariri cearense que há mais do que dez anos uso como "laboratório ao ar livre" para as minhas pesquisas. Essa "região" (entre aspas, veja o meu e-mail de 2 de abril, no qual comentei sobre uma citação do Frémont) fica encravada no coração do Nordeste brasileiro, dominada pelos paredões verdes da Chapada do Araripe. Quando você analisa uma composição colorida de uma imagem de satélite, você logo percebe a imensa mancha verde desse platô no meio do púrpuro do sertão. Muitos autores (por exemplo, PETRONE, 1955; BARROS, 1964; ANDRADE, 1995) não poupam palavras românticas e poéticas sobre a paisagem "ubertosa" do Cariri (ARAÚJO, 1973), sobretudo os vales férteis no seu lado setentrional (SEEMANN, 2008). Enfim, é um lugar peculiar e especial para cartografar.

O que cartografar? Como cartografar? Vou lhe explicar as minhas metodologias cartográficas através de três miniaturas empíricas que resultaram das pesquisas que realizei na região entre 2008 e 2009 (SEEMANN, 2010): narrativas, mapeamentos e performance. Em seguida vou descrever cada estratégia.

A minha primeira estratégia são narrativas cartográficas. Nos últimos anos, surgiram diversas pesquisas sobre a narratividade (por exemplo, PEARCE, 2008; PEARCE \& HERMANN, 2008) e a "vida social" de mapas (PICKLES, 2004). Basicamente, há duas abordagens: a desconstrução da metanarrativa de mapas e a concepção de mapas como formas de narrar histórias (CAOUARD, no prelo). Em outras palavras, "mapas contam histórias, e as histórias que os mapas contam refletem e criam a realidade ao mesmo tempo. Nossa experiência de um lugar é criada ou mudada mediante nossa interação com mapas" (EARLE; GIBSON; WALSH, 2005, p. 249).

Sob essa premissa, mapas são considerados como artefatos contestados que exigem uma leitura "entre suas linhas" para revelar valores, interesses, visões de mundo, atitudes e emoções. Não são produtos acabados e inquestionáveis ("Está aí. Por que está duvidando?"), mas pontos de partida para investigar a experiência humana. Atrás da sua fachada escondem-se "enredos", eventos, acontecimentos, interesses pessoais, políticos e econômicos em diferentes contextos. Como construções sociais e visuais, essas representações cartográficas implicitamente contêm narrativas que estão aguardando a sua descoberta.

Nos meus estudos examinei um conjunto de cerca de 50 mapas históricos eatuais do Cariricearense para escavar histórias cartográficas além dos limites das "paisagens de papel". Essas narrativas me ajudaram a estabelecer um diálogo entre mapas, sua vida social, seus leitores e produtores.

Vou the dar um exemplo. Uma das poucas representações cartográficas históricas que exclusivamente representam a região é o 
Estratégias pós-fenomenológicas para cartografar uma região: narrativas, mapeamentos e performance Jörn Seemann

"Mappa Topographico da Comarca de Crato", (MACEDO, 1871). Você encontra essa obra no site da seção de obras raras do Museu Nacional no Rio de Janeiro. O mapa mostra as terras na divisa entre o Ceará e Pernambuco e a hidrografia do Rio Salgado até o São Francisco. Na parte interior da folha pode-se detectar o traçado de duas linhas finas paralelas, saindo de Boa Vista às margens do "Velho Chico" até o Riacho dos Porcos no sopé da Chapada do Araripe. Eis o projeto original para a transposição do Rio São Francisco! Comecei a ler entre as linhas do mapa. Quem era esse tal de Macedo (1871)? Tratava-se do juiz da Comarca de Crato, Marcos Macedo. Ele usou o mapa para ilustrar como "aumentar o volume das águas nas correntes do Cariri" (MACEDO, 1987[1871]). O juiz apresentou o projeto para os vereadores das cidades de Crato, Barbalha e Jardim, inclusive uma descrição detalhada dos recursos financeiros, materiais e humanos usados, entre esses as 24 comportas de madeira e os obreiros alemães com "educação acadêmica, das mais perfeitas" que "deverão ser solteiros e moços, a fim de economizar-se as despesas com a passagem das famílias, e se poderem mais facilmente habituar à nossa alimentação diferente da sua" (MACEDO, 1987, p. 91). Em 1871 o projeto não encontrou ouvidos abertos e foi arquivado. Portanto, mais do que 130 anos depois dessa tentativa de Macedo, o debate polêmico sobre o sentido ou não sentido da transposição do São Francisco está mais vivo do que nunca. Usei esse exemplo para lhe mostrar a narratividade de mapas e como representações cartográficas podem até ter impactos no presente.

Na minha análise de todos os mapas históricos que, de uma forma ou outra, representavam o Cariri consegui preencher várias lacunas na geografia e história regional. Os mapas me serviram como um "portão

3 Disponível em <http://www.obrasraras.museunacional.ufrj.br/o/o011/mapa.pdf>. Acesso: 19/12/2012.

Geograficidade | v.3, n.2, Inverno 2013

ISSN 2238-0205 de entrada" ou um "gatilho" para extrair discursos e histórias sobre a geograficidade e historicidade da região, pedaços no quebra-cabeça da história cartográfica no Sul do Ceará.

Deixe-me falar agora da minha segunda estratégia, o mapeamento. Quando iniciei as minhas pesquisas sobre cartografia e cultura mais do que uma década atrás (SEEMANN, 2001), o geógrafo inglês Denis Cosgrove foi a minha maior inspiração (COSGROVE, 1999). No prefácio de uma coletânea sobre mapeamentos, ele brinca com a palavra "mapeamento", tanto no seu sentido "no-pé-da-letra" bem como metaforicamente. Cosgrove ressalta que o ato de mapear é uma tentativa de medir o mundo, não necessariamente em termos matemáticos, mas também nos seus sentidos figurativo, imaginado ou desejado (COSGROVE, 1999, p. 2-3).

Reparei que mapas mentais seriam mapeamentos por excelência para mostrar como desenhos no papel podem se tornar criações e re-criações do mundo. Logo comecei a elaborar um projeto sobre as representações mentais do Cariri. Entre junho de 2008 e julho de 2009 juntei mais do que 350 mapas mentais da região, produzidos por alunos e alguns professores do Curso de Geografia da Universidade Regional do Cariri (SEEMANN, no prelo). Meu desafio era coletar e analisar esse material para poder extrair ideias sobre a cultura cartográfica, o conhecimento geográfico e a cartograficidade na região. Os mapas mentais abriram uma vasta gama de visões regionais expressas em forma (carto)gráfica.

Cheguei à conclusão de que até o traçado de linhas mais simples ou um rabisco aparentemente insignificante poderiam contribuir para compreender como uma região é imaginada e construída cartograficamente. Os mapas não eram meras representações do espaço, mas também espaços de representação para expressar orgulho local, comunicar idéias sobre a região ou mostrar "maptitudes". Em 
Estratégias pós-fenomenológicas para cartografar uma região: narrativas, mapeamentos e performance

Jörn Seemann

outras palavras, desenhar uma linha em um mapa pode ser como contar uma história (INGOLD, 2008, p.90). Mas que tipo de história? O mapa mental requer uma leitura "entre as suas linhas" que vá além da superfície lisa no papel e que estabeleça uma ligação entre produtos e processos e os mapeadores e sua identidade regional. Passei três ou quatro meses analisando os mapas e tentando elaborar uma metodologia qualitativa para classificá-los e encontrar um sentido nesses desenhos. Cheguei a gravar depoimentos dos alunos para tirar dúvidas e descobrir por que eles representavam e/ou apresentavam a região de uma determinada maneira. Ainda me lembro de um dos estudantes que produziu um mapa do Cariri em vermelho, porque recentemente havia muitas queimadas. Quem disse que não se pode rir nas aulas de cartografia?

Quero falar de mais uma estratégia. Talvez você tenha percebido que concebo os mapas não como produtos, mas como processos performativos e "corporificados", nos quais se enfatizam a ação e o movimento e não a representação. Assim sendo, mapas podem ser compreendidos como ações-em-movimento em constante formação. O geógrafo inglês Chris Perkins (2009, p. 126) usa o termo (e)motional mapping para indicar as relações entre emoção e moção (movimento). Para mapear, precisamos nos locomover, já que não existe aquele olhar cartográfico onisciente que possa permitir uma visão total do espaço. Esses mapeamentos não se realizam sem um entrosamento ou engajamento do mapeador, de modo que as emoções humanas também se imprimem nas paisagens cartográficas.

Vou lhe dar um exemplo prático para explicar melhor essa idéia (SEEMANN, 2012). Nos meus estudos cartográfico-culturais no Cariri, resolvi seguir o percurso de Francisco Freire Alemão, um botânico brasileiro que em meados do século XIX visitou a região. Freire Alemão

Geograficidade | v.3, n.2, Inverno 2013 ISSN 2238-0205 era presidente da Comissão Científica de Exploração (1859-1861) que tinha como objetivo

explorar algumas das províncias menos conhecidas do Brasil, com a obrigação de formarem também para o Museu Nacional uma coleção de produtos dos reinos orgânico e inorgânico, e de tudo quanto possa servir de prova do estado de civilização, indústria, usos e costumes dos nossos indígenas. (BRAGA, 1962, p. 17)

Durante a sua estadia de três meses no Cariri, Freire Alemão meticulosamente anotou as suas observações sobre plantas, paisagens e pessoas no seu diário (FREIRE ALEMÃO, 2007 [1859-1860]). No começo do ano 1860, ele realizou uma viagem de dez dias, durante a qual atravessou a Chapada do Araripe várias vezes. Decidi reconstruir a trajetória dessa excursão e comparar as suas observações com os mapeamentos e performances da minha autoria.

No dia 30 de janeiro de 1860, às nove horas da manhã, Freire Alemão e os seus companheiros saem da cidade de Crato no Ceará e iniciam a sua subida nas encostas da Chapada do Araripe, rumo a Exu em Pernambuco. Imagino o botânico montado no seu cavalo, em trote lento, enfrentando a trilha poeirenta para o platô e passando por plantações de cana-de-açúcar, nas quais a população nativa cumprimenta os viajantes com curiosidade gentil. Enquanto isso, meu meio de transporte é uma van Volkswagen surrada da universidade, máquina de metal cansada que se arrasta para o topo do platô na primeira marcha. Estou sentado ao lado do motorista, com quatro cartas topográficas na escala 1:100.000 no meu colo. Infelizmente, a área do meu estudo fica justamente nas bordas desses quatro mapas, o que dificulta bastante os meus mapeamentos. O motorista está em um "vôo rasante" e mal consigo ver a paisagem. Tiro fotos do carro. Todas têm a moldura do pára-brisa, inclusive os limpadores. 
Estratégias pós-fenomenológicas para cartografar uma região: narrativas, mapeamentos e performance Jörn Seemann

Durante o percurso, perdemos o caminho várias vezes, porque o motorista anda muito rápido. Apenas para o carro quando insisto muito e falo mais alto. Para ele, o que importa não é o percurso, mas a chegada. As cartas topográficas modernas também não ajudam. Por exemplo, o nome de um dos lugares na nossa trajetória, Caraíba, aparece três vezes no mapa e não descobrimos qual era o lugar correto. Pegamos uma trilha estreita quase intransitável. Os galhos das arvores batem no pára-brisa e arranham a carroceria da van que está literalmente pulando por cima da superfície irregular da estrada que o meu mapa traiçoeiramente classifica como "rodovia, transitável em tempo bom e seco, revestimento solto." Paramos em uma pequena propriedade no caminho, e o dono da casa começa a rabiscar algumas linhas no chão na sua frente para nos explicar as direções. Tinha uma casa de taipa grande na vizinhança que não existe mais, nem no meu mapa. A única impressão que ficou foi o desenho efêmero no chão.

Qual é o sentido dessa história? Quero lhe mostrar que nossas pré-concepções, percepções e concepções do espaço ganham um significado diferente quando estamos em movimento. Geografia e cartografia podem ser vividas e experimentadas quando estamos andando a pé ou de bicicleta, dirigindo um carro ou viajando de avião (por exemplo, WYLIE, 2005; SPINNEY, 2006; MERRIMAN, 2007; ADEY, 2010). Para ir mais longe, podemos dizer que "mobilidade é espacial e central para a experiência humana, como uma maneira de ser-nomundo (CRESSWELL, 2006, p. 3). Outro dia li sobre um geógrafo que atravessou o Canadá para superar a morte da sua esposa (COULIS, 2010). Esse "hermeneuta de bicicleta" pedalou 10.000 quilômetros e usou os mapas que desenhou da sua viagem para expressar a sua autoconsciência gerada pela combinação de corpo, movimento e pensamento.
Esse relato cartográfico pessoal e íntimo me ajudou a estabelecer uma ligação com a fenomenologia. Minha experiência é parte da minha autocartografia, que pode ser definida como "os processos mentais e materiais que objetivam mapear espaços e lugares em relação com a experiência humana e as representações visuais (mapas, fotos, etc.) da realidade" (SEEMANN, 2010, p. 244). No caso das minhas pesquisas no Nordeste, essa autocartografia dizia respeito às minhas próprias maneiras de mapear o Cariri e os respectivos movimentos, representações e performances corporais, baseados na minha experiência vivida na região.

Tenho certeza que você ficou com muitas dúvidas sobre esses mapeamentos em movimento. Ficaria feliz se pudesse me mandar os seus comentários sobre as minhas cartografias pós-fenomenológicas. Ou será que já é uma pós-cartografia?

Abraços pós do seu amigo Jörn.

\section{E-MAIL 5, 30 DE SETEMBRO DE 2012}

\section{Cara amiga,}

A minha mesa redonda foi um sucesso. Havia uma discussão animada sobre as minhas cartografias pós-fenomenológicas. Voltei para casa com muitas ideias na bagagem e já estou na fase de conclusão para submeter o meu artigo para publicação. Acabei de receber o texto mais recente do grande geógrafo humanista Yi-Fu Tuan, uma reflexão sobre as concordâncias e discordâncias entre cartografia e humanismo (TUAN, 2011). Ele afirma que "ser humano significa ser um cartógrafo, envolvido com o mapeamento e a compreensão do mundo 'lá fora'" (TUAN, 2011, p. 73). Portanto, ao mesmo tempo, Tuan alerta que há alguns componentes incompatíveis entre essas duas áreas de conhecimento. Para ele, não conseguimos visualizar fidedignamente 
o bem ou o mal ou provocar emoções através de mapas por causa do uso de padrões abstratos e símbolos convencionais (TUAN, 2011, p. 72). As convenções e a linguagem seriam os limites das nossas experiências, do nosso mundo? Haja Wittgenstein! Não concordo com essa afirmação. Não foi exatamente o contrário que quis mostrar no meu artigo? Na verdade, o discurso sobre a objetividade dos mapas continua dominando os nossos pensamentos. Ainda não aceitamos os mapas como parte integrante das nossas vidas: "Estamos cercados pela riqueza de dados cartográficos e esquecemo-nos de nós mesmos e das nossas próprias histórias a favor da autoridade de um cartógrafo externo" (EARLE; GIBSON; WALSH, 2005, p. 249). O que falta é explorar mais a subjetividade dos mapas e seu potencial como forma de comunicação de idéias e expressão de emoções e valores. Para isso, o ponto de partida somos nós mesmos. Faço das palavras do geógrafo Keith Lilley as minhas:

Desenhar um mapa envolve o sujeito, tornando o mapeamento uma experiência pessoal e reflexiva. Como resultado, o mapa é um 'mapa' de experiências e certamente pode ser lido como tal. Sua materialidade, sua textura e a sensação ao tocá-lo são uma parte crítica da habilidade do mapa de provocar diálogos que, por sua vez, serão impressos na sua superfície. (LILLEY, 2000, p. 373)

Tenho mais um último ponto para fechar o meu pensamento sobre sentido de lugar, mapas, fenomenologia e regiões. É mais uma reflexão do que uma afirmação. De acordo com o antropólogo britânico Tim Ingold, fazer mapas significa conectar pontos, já que a compreensão de lugares não se baseia em sítios e as suas posições, mas naquilo que esses lugares nos contam. Lugares não têm locais, mas histórias. Amarrados pelos itinerários das pessoas, lugares não existem no espaço, mas são nodos em uma matriz de movimentos
(INGOLD, 2000, p.219). Não é por coincidência que Ingold chama essa matriz de região: "Enquanto usar um mapa significa marcar o percurso de uma localização para outra no espaço, navegação, por outro lado, é uma questão de se mover de um lugar para outro em uma região (INGOLD, 2000, p. 219, ênfase no original). Mapear uma região não é uma cartografia de lugares, mas são os movimentos no deslocamento entre eles.

Espero ter fechado o círculo do meu pensamento com essas últimas observações sobre regiões. O nosso desafio é como captar essas cartografias em movimento. Navegar é preciso e ainda há muitas histórias da nossa existência humana a serem mapeadas. Tenho a impressão de que essas reflexões pós-fenomenológicas poderiam abrir novos caminhos.

Abraços do seu amigo Jörn.

PS: No anexo, estou the mandando a minha bibliografia para podermos estreitar nosso diálogo.

\section{REFERÊNCIAS}

ADAMS, Paul C.; HOELSCHER, Steven; TILL, Karen. Place in context. Rethinking humanist geographies. In: ADAMS, Paul C.; HOELSCHER, Steven; TILL, Karen, orgs., Textures of place. Exploring humanist geographies. Minneapolis: University of Minnesota Press, 2001, p. xiiixxxiii.

ADEY, Peter. Aerial life: spaces, mobilities, affects. Oxford: WileBlackwell, 2010.

ANDERSON, Benjamin. Comunidades imaginadas. Reflexões sobre a origem e a difusão do nacionalismo. São Paulo: Companhia das Letras, 2008. 
Estratégias pós-fenomenológicas para cartografar uma região: narrativas, mapeamentos e performance

Jörn Seemann

ANDERSON, Ben; HARRISON, Paul. Taking-place: nonrepresentational theories and geography. Aldershot: Ashgate, 2010.

ANDRADE, Manuel Correia. A terra e o homem no nordeste. 5.ed., São Paulo:Atlas, 1995. ARAÚJO, Padre Antônio Gomes de. Povoamento do Cariri. Crato/CE: Faculdade de Filosofia, 1973.

BACHELARD, Gaston. A poética do espaço. In: BACHELARD, Gaston. A Filosofia do não; O novo espírito cientifico; A poética do espaço. São Paulo: Abril Cultural, 1978, p. 181-354 (Série Os Pensadores).

BARNES, Trevor; GREGORY, Derek. Agents, subjects, and human geography. In: BARNES, Trevor; GREGORY, Derek, orgs., Reading human geography. The poetics and politics of inquiry. London: Arnold, 1997, p. 356-363

BARROS, Haidine da Silva. O Cariri cearense. O quadro agrário e a vida urbana, Revista Brasileira de Geografia, Rio de Janeiro, v. 26, n. 4, p. 549-592, 1964

BERNARDES, Lísia Maria; BERNARDES, Nilo. A pesca no litoral do Rio de Janeiro, Revista Brasileira de Geografia, Rio de Janeiro, v. 12, n. 1, p. $17-54,1950$.

BRAGA, Renato. História da Comissão Científica de Exploração. Fortaleza: Imprensa Universitária do Ceará, 1962.

CAQUARD, Sébastien. Cartography I: Mapping narrative cartography, Progress in Human Geography (online first), 07/11/2011. [no prelo.]

CLAVAL, Paul. Regional geography: past and present (a review of ideas, approaches and goals), Geographia Polonica, Varsóvia, v. 80, n. 1, p. 25-42, 2007.

CLOKE, Paul; PHILO, Chris; SADLER, David. Approaching human geography. An introduction to contemporary theoretical debates. New York: Guilford, 1991.

CORRÊA, R. L. Região e organização espacial. São Paulo: Ática, 1986.
COSGROVE, Denis. Introduction: Mapping meaning. In: COSGROVE, Denis. (org.) Mappings. London: Reaktion Books, 1999, p. 1-23.

COULIS, Michael. Hermeneut on a bike: Eleven geo-logical lessons in love and landscapes. In: RANGEL, Matthew. (org.) Journeys beyond the neatline. Expanding the boundaries of cartography. Edmonton: University of Alberta Libraries, 2010, sem paginação.

CRESSWELL, Tim. On the move. Mobility in the modern Western world. London: Routledge, 2006.

DODGE, Martin; PERKINS, Chris. The "view from nowhere"? Spatial politics and cultural significance of high-resolution satellite imagery, Geoforum, v. 40, n. 4, p. 497-501, 2009.

EARLE, Schuyler; GIBSON, Rich; WALSH, Jo. Mapping hacks. Tips and tools for electronic cartography. Sebastopol, CA: O'Reilly, 2005

FREIRE ALEMÃO, Francisco. Diário de viagem de Francisco Freire Alemão. Crato - Rio de Janeiro, 1859-186o. Fortaleza: Museu do Ceará, 2007 [1859-1860].

FRÉMONT, Armand. Région: Espace vécu. Paris: PUF, 1976.

GILBERT, Anne. The new regional geography in English and Frenchspeaking countries, Progress in Human Geography, v. 12, n. 2, p. 208228,1988

GOMES, Paulo César da Costa. O conceito de região e sua discussão. In: CASTRO, Iná E.; GOMES, Paulo C. da C.; CORRÊA, Roberto L. (orgs.) Geografia: conceitos e temas. Rio de Janeiro, Bertrand Brasil, 1995, p. $49-76$

HAESBAERT. Regional-global: dilemas da região e da regionalização na Geografia contemporânea. Rio de Janeiro: Bertrand Brasil, 2010.

HENDERSON, George. Region. In: GREGORY, Derek et al. (orgs.) Dictionary of human geography. $5^{\text {a }}$ edição. Oxford: Wiley-Blackwell, 2009, p. 630-632. 
Estratégias pós-fenomenológicas para cartografar uma região: narrativas, mapeamentos e performance

Jörn Seemann

HUDSON, John C. Across this land. A regional geography of the United States and Canada. Baltimore: Johns Hopkins University Press, 2002.

INGOLD, Tim. The perception of the environment. Essays on livelihood, dwelling and skill. London: Routledge, 2000.

. Lines. London: Routledge, 2008.

JORDAN, Terry. Perceptual regions in Texas, Geographical Review, Washington, v. 68, n. 3, p. 293-307, 1978.

LEA, Jennifer Jane. Post-phenomenology/post-phenomenological geographies. In: KITCHIN, Rob; THRIFT, Nigel. (orgs.) International encyclopedia of human geography. Elsevier, Oxford, 2009, p.373-378.

LEITE, Edgar. O problema da terra no Brasil, Revista Brasileira de Geografia, Rio de Janeiro, v. 21, n. 2, p. 127-146, 1959.

LENCIONI, Sandra. Região e geografia. São Paulo: EDUSP, 1999.

LILLEY, Keith. Landscape mapping and symbolic form. Drawing as a creative medium in cultural geography. In: COOK, lan et al. (orgs.) Cultural turns/geographical turns. Perspectives on cultural geography. Nova York: Prentice Hall, 2000, p.370-386.

LORIMER, Hayden. Cultural geography: the busyness of being "morethan-representational", Progress in Human Geography, v. 29, n. 1, p. 83-94, 2005.

MACEDO, Marcos Antônio de. Observações sobre as secas do Ceará e os meios de aumentar o volume das águas nas correntes do Cariri. In: ROSADO, Vingt-Um; ROSADO, América (orgs.) Décimo quarto livro das secas (Coleção Mossoroense, 369). Mossoró: ESAM, 1987, p. 15166. (originalmente publicado em: Revista do Instituto Politécnico do Brasil, n. 11, Rio de Janeiro, 1871, p. 1-78). Disponível em: <http://www. colecaomossoroense.org.br/pics/ 14_Livro_das_Secas.pdf>. Acesso em: 30/10/2012

MERLEAU-PONTY, Maurice. Fenomenologia da percepção. São Paulo: Martins Fontes, 1994
MERRIMAN P. Driving spaces: a cultural-historical geography of England's M1 motorway. Oxford: Wiley-Blackwell, 2007.

NAGEL, Thomas. The view from nowhere. Oxford: Oxford University Press, 1989.

PAASI, Anssi. Place and region: regional worlds and words, Progress in Human Geography, v. 26, n. 6, p. 802-811, 2002.

PEARCE, Margaret W. Framing the days: place and narrative in cartography, Cartography and Geographic Information Science, v. 35, n. 1, p. 17-32, 2008.

PEARCE, Margaret W., HERMANN, Michael J. They would not take me there: people, places, and stories from Champlain's travels in Canada, 1603-1616. Orono, ME: University of Maine CanadianAmerican Center, 2008.

PERKINS, Chris. Performative and embodied mapping. In: KITCHIN, Rob; THRIFT, Nigel. (orgs.) International encyclopedia of human geography, vol. 8. Amsterdam/Boston: Elsevier, 2009, p.126-132.

PETRONE, Pasquale. Contribuição ao estudo da região do Cariri no Ceará, Boletim Paulista de Geografia, São Paulo, n. 19, p. 3-29, 1955.

PICKLES, John. A History of spaces. Cartographic reason, mapping and the geo-coded world. London: Routledge, 2004

PRICE, Marie.TheVenezuelan Andes and the geographical imagination, Geographical Review, v. 86, n. 3, p. 334-355, 1996.

PUDUP, Mary Beth. Arguments within regional geography, Progress in Human Geography, v. 12, n. 3, p. 369-390, 1988

REICHART, Dagmar. Obituary, Ethics, Place and Environment, v. 1, n. 2, p. 157-164, 1998.

ROSE, Mitch; WYLIE, John. Landscape - Part II. In: AGNEW, John; DUNCAN, James (orgs.) The Wiley-Blackwell companion to human geography. Oxford: Wiley-Blackwell, 2011, p. 221-234. 
SAINT-EXUPÉRY. O pequeno príncipe. Rio de Janeiro: Editora Agir, 1967.

SANTOS, Milton. A cidade de Jequiê e sua região, Revista Brasileira de Geografia, Rio de Janeiro, v. 18, n. 1, p. 71-112, 1956.

SAYER, Andrew. The "new" regional geography and problems of narrative, Environment and Planning D, v. 7, n. 3, p. 253-276, 1989.

SEEMANN, Jörn. Cartografias culturais na Geografia Cultural: entre mapas da cultura e a cultura dos mapas, Boletim Goiano de Geografia, Goiânia, v. 21, n. 2, p. 61-82, 2001.

Uma região - muitas geografias: olhares geográficos, narrativas e alteridades no Cariri cearense, Cadernos de Cultura e Ciência (URCA), Crato, v. 3, p. 1-17, 2008.

Regional narratives, hidden maps, and storied places: cultural cartographies of the Cariri region, Northeast Brazil. 2010. Tese (Doutorado em Geografia). Department of Geography \& Anthropology, Louisiana State University, Baton Rouge.

Cartographic story-telling, performance of way-finding and (e)motional mapping in the Cariri region, State of Ceará, Boletim de Geografia (UEM), Maringá, v. 30, p. 5-13, 2012.

. Histórias da cartografia, imersão em mapas e carto-falas: métodos para estudar culturas cartográficas. In: CAZETTA, Valeria; OLIVEIRA JR., Wenceslao M. de (orgs.) Grafias do espaço. Imagens da educação geográfica contemporânea. Campinas: Átomo \& Alínea. [no prelo.]
SETZER, José. Os solos de Itapecerica, SP, Revista Brasileira de Geografia, Rio de Janeiro, v. 13, n. 4, p. 515-546, 1951.

SPINNEY, Justin. A place of sense: a kinaesthetic ethnography of cyclists on Mont Ventoux, Environment and Planning D, v. 24, n. 5, p. 709-732, 2006.

THRIFT, Nigel. Visando o âmago da região. In: GREGORY, Derek; MARTIN, Ron; SMITH, Graham (orgs.) Geografia humana: sociedade, espaço e ciência social. Rio de Janeiro: Jorge Zahar Editor, 1996, p. 215-247.

Non-representational theory: space, politics, affect. London: Routledge, 2007.

TUAN, Yi-Fu. Cartography and humanism. Concordances and discordances, Glimpes, v. 8, p. 66-73, 2011.

TURRA Neto, Nécio. Enterrado, mas ainda vivo! Identidade punk e território em Londrina. 2001. Dissertação (Mestrado em Geografia). Universidade Estadual de Londrina, Londrina.

WHATMORE, Sarah. Materialist returns: practicing cultural geography in and for a more-than-human-world, Cultural Geographies, v. 13, n. 4, p. 600-609, 2006.

WOOD, Denis. Book review: The human experience of space and place, Environment and Behavior, v. 14, n. 4, p. 503-506, 1982.

WYLIE, John W. A single day's walking: narrating self and landscape on the Southwest Coast Path, Transactions of the Institute of British Geographers, Londres, v. 30, n. 2, p. 234-247, 2005.

Submetido em Outubro de 2012. Revisado em Dezembro de 2012. Aceito em Dezembro de 2012. 